\title{
Variable Characteristic
}

National Cancer Institute

\section{Source}

National Cancer Institute. Variable Characteristic. NCI Thesaurus. Code C43371.

A characteristic or attribute of an object, event, or other entity under observation that can assume more than one value and by which a classification can be assigned. 